\title{
Editorial
}

\section{Intern Medical Officers}

Journal of the Ceylon College of Physicians, 2013, 44, 1

Interns are a neglected lot. They are the most junior of the doctors in the state service. They need guidance, proper supervision, training and mentoring. When in other countries the interns start work soon after their final results, in ours they waste over six months waiting till the Ministry is ready. The system of giving placements are done using the common merit order but it is flawed. Appointments are prioritized according to the station rather than the specialty. Ideally the candidates should be able to select the specialty i.e. Medicine, Surgery, Paediatrics and Obstetrics and Gynaecology and all given the chance to do medicine or one of its allied specialties like Cardiology, Neurology and Respiratory medicine etc. The paucity of available medicine slots can be overcome by this method and this would be far better than doing Paediatrics and Obstetirics as the combination or as it sometimes happen Surgery and Gynaecology or Paediatrics and Paediatric surgery. These latter combinations are not suitable foundations for beginners. In UK the training spreads over two years and the first year includes 3 to 4 rotations in medical and surgical specialities such as general surgery, urology, GI surgery, geriatrics, cardiology, chest medicine etc. In Australia the first year includes medicine and surgery four months each and two elective appointments of the candidates choice of two months each. But our authorities have taken the easy way out sacrificing educational and training principles, slotting interns haphazardly into available postings. This needs changed urgently into a more rational method with the goal of providing a better training in the first year. To add to their woes these beginners don't have a formal training programme or objectives. They don't have dedicated teaching hours to prepare for postgraduate exams resulting in low standards later. Other countries have e-portfolio assessments regularly with structured assessments and feedback. But our interns' training objective appears to be work, work and work.

They are on call every other day and work in the next morning after having been up the whole night jeopardizing their health and the patients as well. There had been some presentations at recent scientific meetings of SLMA and CCP about the sleep and working patterns of interns and the results show that they are sleep deprived to extents where it can affect their decision making. Their living quarters are very inadequate and facilities available for meals are grossly inadequate. Most interns lose weight during this period. Their salaries are only a mere Rs. 30,000 and they work 24 hours without any overtime pay. UK NHS pay their interns according to the on calls they do. SLMC, Medical Faculties and the Health Ministry should get together to resolve these important issues of these young doctors and they don't have a voice because they do not belong to any trade union. SLMC while dealing with the ever increasing problem of foreign graduates seem to have lost interest in the Srilankan graduates. But their welfare should be our responsibility, the senior doctors they are working with.

\section{Saman Gunatilake}

Editor 